\title{
NiMnGa/Si Shape Memory Bimorph Nanoactuation
}

\author{
Franziska Lambrecht ${ }^{1} \cdot$ Christian Lay $^{1} \cdot$ Iván R. Aseguinolaza $^{2} \cdot$ \\ Volodymyr Chernenko ${ }^{2,3} \cdot$ Manfred Kohl $^{1}$
}

Published online: 18 October 2016

(c) ASM International 2016

\begin{abstract}
The size dependences of thermal bimorph and shape memory effect of nanoscale shape memory alloy (SMA)/Si bimorph actuators are investigated in situ in a scanning electron microscope and by finite element simulations. By combining silicon nanomachining and magnetron sputtering, freestanding $\mathrm{NiMnGa} / \mathrm{Si}$ bimorph cantilever structures with film/substrate thickness of 200/250 $\mathrm{nm}$ and decreasing lateral dimensions are fabricated. Electrical resistance and mechanical beam bending tests upon direct Joule heating demonstrate martensitic phase transformation and reversible thermal bimorph effect, respectively. Corresponding characteristics are strongly affected by the large temperature gradient in the order of $50 \mathrm{~K} / \mu \mathrm{m}$ forming along the nano bimorph cantilever upon electro-thermal actuation, which, in addition, depends on the size-dependent heat conductivity in the $\mathrm{Si}$ nano layer. Furthermore, the martensitic transformation temperatures show a size-dependent decrease by about $40 \mathrm{~K}$ for decreasing lateral dimensions down to $200 \mathrm{~nm}$. The effects of heating temperature and stress distribution on the nanoactuation performance are analyzed by finite element simulations revealing thickness ratio of SMA/Si of $90 / 250 \mathrm{~nm}$ to achieve an optimum SME. Differential thermal expansion and thermo-elastic effects are
\end{abstract}

Franziska Lambrecht

franziska.lambrecht@kit.edu

1 Institute of Microstructure Technology, Karlsruhe Institute of Technology (KIT), 76131 Karlsruhe, Germany

2 BCMaterials, and University of Basque Country (UVP/EHU), 48080 Bilbao, Spain

3 Ikerbasque, Basque Foundation for Science, 48013 Bilbao, Spain discriminated by comparative measurements and simulations on $\mathrm{Ni} / \mathrm{Si}$ bimorph reference actuators.

Keywords NiMnGa $<$ materials $\cdot$ Mechanical behavior . Shape memory films

\section{Introduction}

Shape memory alloys (SMAs) experience a reversible, diffusionless, solid-to-solid phase transformation by spontaneous distortion of the crystal lattice. The shape memory effect (SME) is associated with highest work outputs per unit volume in the order of $10^{7} \mathrm{Jm}^{-3}$ making SMAs interesting materials for nano-electro-mechanical systems (NEMS) [1]. Here, we focus on ferromagnetic SMA $\mathrm{NiMnGa}$, which exhibits thermal shape memory effect and magnetic-field induced strain (MFIS) effect reaching up to $12 \%$ in bulk single crystals [2]. In polycrystalline form, however, magneto strain is reduced to almost zero since twin boundary motion is inhibited by constraints imposed by grain boundaries [3]. These constraints may be reduced by shrinking the characteristic length scale of the sample down to the grain size approaching an oligocrystalline structure. Applying this approach to $\mathrm{NiMnGa}$ foams resulted in an increase in MFIS up to $8.7 \%$ [4]. Nanoindentation experiments indicate shape memory effect and superelasticity in nanoscale imprints [5, 6]. However, due to the complex loading states, extrapolation of these results to nanostructures is difficult. As an alternative approach, compression measurements have been performed on microand nanopillars revealing interesting size-dependent effects $[7,8]$. Yet, limitations in fabrication technology as well as in measurement methods are major obstacles to gain a 
better understanding of scaling effects on the thermomechanical properties of SMAs.

This paper focuses on the size dependences of thermal bimorph and shape memory effect of nanoscale $\mathrm{NiMnGa} / \mathrm{Si}$ bimorph actuators fabricated by electron beam lithography and magnetron sputtering. A series of test devices of the same stoichiometric composition is presented showing film/substrate thickness of $200 / 250 \mathrm{~nm}$ with decreasing lateral dimensions down to $200 \mathrm{~nm}$. Such devices are of considerable interest for bidirectional actuation at the nanometer scale using both thermal SME as well as thermal bimorph effect. Magnetic properties are an interesting topic on their own and will not be addressed here. Major challenges of this investigation are the unknown effects of nanofabrication technologies, the complex thermo-elastic coupling due to inhomogeneous stress- and temperature profiles as well as possible size-dependent effects on the nanometer scale. The different issues will be addressed by comparing experimental and finite element simulation results on nanoscale $\mathrm{NiMnGa} / \mathrm{Si}$ bimorph actuators, $\mathrm{Ni} / \mathrm{Si}$ bimorph actuators as well as NiMnGa films on Si substrate. Owing to their small dimensions, electrical and mechanical performance characteristics of the nanodevices are determined in situ in a scanning electron microscope (SEM) environment.

\section{Material Properties}

The NiMnGa films are prepared by DC magnetron sputtering onto a common $\mathrm{Si}$ wafer. First, a 10-nm-thick $\mathrm{Cr}$ buffer layer is deposited at room temperature to compensate for the large lattice mismatch between $\mathrm{NiMnGa}$ and $\mathrm{Si}$ crystal structure. Then, the NiMnGa film is deposited at $500{ }^{\circ} \mathrm{C}$ to promote a good crystallinity and to adjust phase transformation temperatures. The different deposition rates of the constituents at high deposition temperature lead to a deviation between target and thin film composition. While the target composition is $\mathrm{Ni}_{49.9} \mathrm{Mn}_{27.8} \mathrm{Ga}_{22.3}$ (at.\%), the final thin film composition is determined to be $\mathrm{Ni}_{53.9}$ $\mathrm{Mn}_{24.7} \mathrm{Ga}_{21.4}$ using energy dispersive X-ray spectroscopy. $\mathrm{X}$-ray diffraction measurements reveal a pseudo-tetragonal $10 \mathrm{M}$ martensitic structure at room temperature. Scanning Electron microscopy measurements show a non-epitaxial morphology with average grain size of $75 \mathrm{~nm}$ in cross section.

Figure 1 shows the anomalous change of electrical resistance due to the martensitic phase transformation, which is characterized upon cooling by an increase of electrical resistance between the martensitic start and finish temperatures, $M_{\mathrm{S}}$ and $M_{\mathrm{F}}$, respectively. Cyclic heating and cooling reveals a narrow thermal hysteresis of only about $1 \mathrm{~K}$ reflecting the good compatibility of the austenite and

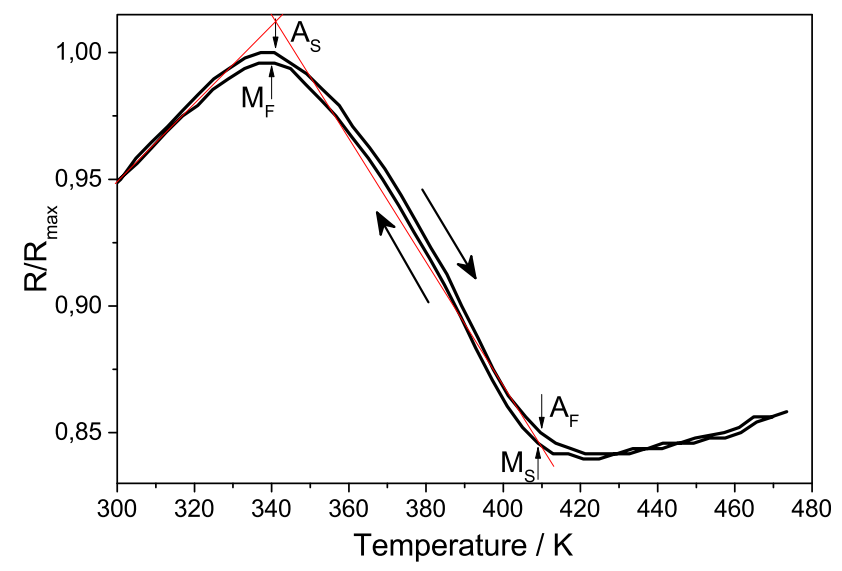

Fig. 1 Normalized electrical resistance characteristics versus temperature of a reference NiMnGa thin film of $1 \mu \mathrm{m}$ thickness on a Si substrate. Start and finish temperatures of phase transformation between martensitic (M) and austenitic (A) phase are determined by the tangential method

martensite crystal structure. The electrical resistance measurements are executed with a four-point measurement setup to avoid the influence of contact resistances.

\section{Layout and Nanofabrication}

$\mathrm{NiMnGa} / \mathrm{Si}$ bimorph nanoactuators are designed as doublebeam cantilevers to enable electro-thermal actuation by Joule heating as well as simultaneous measurements of electrical resistance and mechanical deflection. The layout of the double-beam cantilevers is shown in Fig. 2a. It contains a large contact pad which is directly connected to a source measure unit, whereas individual bimorphs are contacted by two nano-manipulators. Based on this layout, a series of test devices is designed as listed in Table 1 featuring beam lengths and widths down to $8.3 \mu \mathrm{m}$ and $200 \mathrm{~nm}$, respectively. For comparison of different length scales, a $\mathrm{NiMnGa} / \mathrm{Si}$ reference device is designed with film/substrate thickness of $1000 / 1000 \mathrm{~nm}$ and $2000 \mathrm{~nm}$ lateral width.

The NiMnGa/Si bimorph nanoactuators are fabricated by a combination of ultra-high resolution electron beam lithography (EBL) and reactive-ion etching (RIE) steps. The transfer of the primary resist pattern created by EBL into the FSMA layer is a main challenge in fabrication as RIE of Ni is well-known to produce non-volatile reaction products. In addition, dry etching of Si may cause defects in the NiMnGa film and possible degradation of the SME. One approach to cope with these problems is to nanomachine the Si substrate prior to deposition of the NiMnGa film [9].

The fabrication consists of four main process steps. First, EBL is performed on a SOI wafer with a 500-nm- 


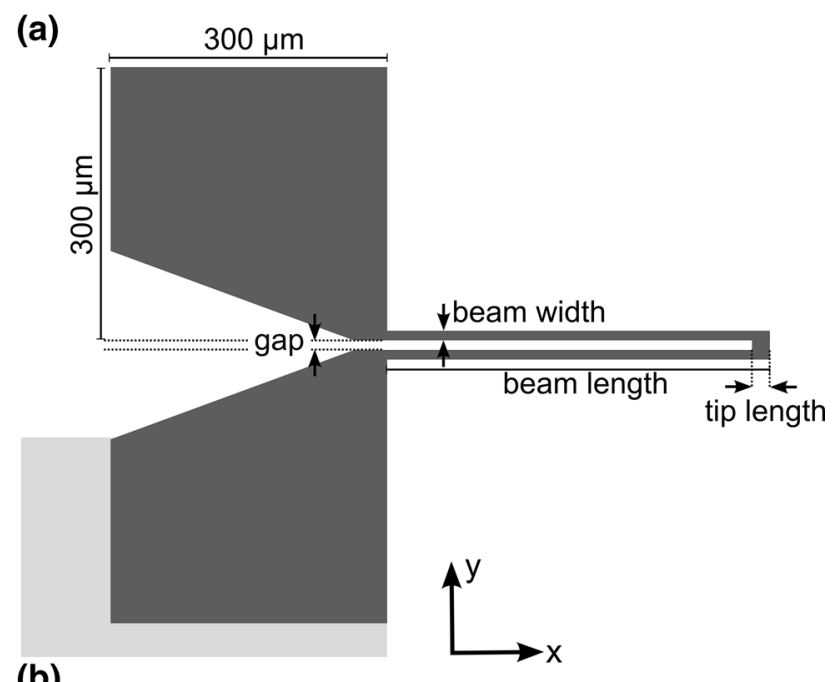

(b)

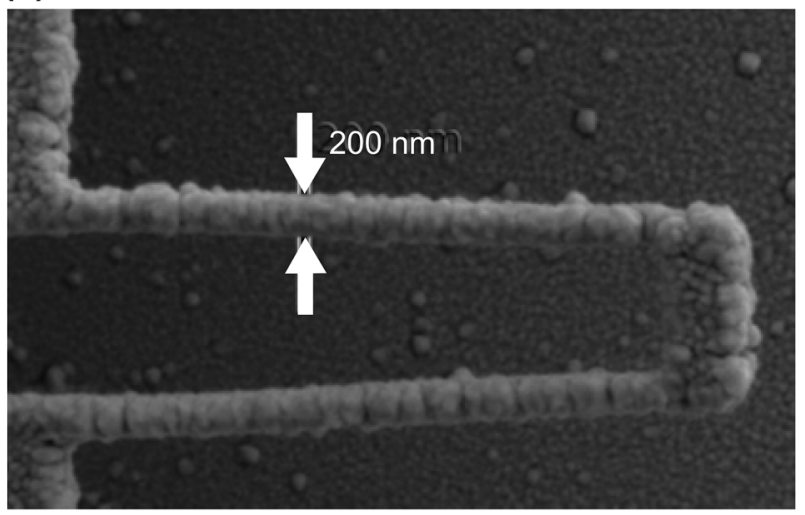

(c)

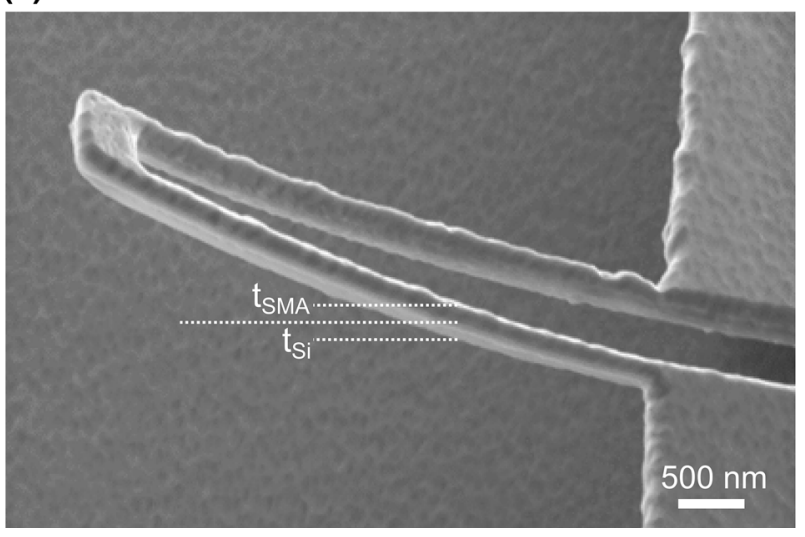

Fig. 2 a Schematic layout of a NiMnGa/Si bimorph nanoactuator. b SEM micrograph of a $\mathrm{NiMnGa/Si}$ bimorph nanoactuator (top view) showing a beam cantilever width of approximately $200 \mathrm{~nm}$. c SEM micrograph of a $\mathrm{NiMnGa} / \mathrm{Si}$ bimorph nanoactuator (side view) after removal of sidewall deposition showing the layers of $\mathrm{Si}$ and $\mathrm{NiMnGa}$ with thicknesses $t_{\mathrm{SMA}}$ and $t_{\mathrm{Si}}$. The nanoactuator is deflected in out-ofplane direction at room temperature

thick single crystalline Si device layer and a 4- $\mu$ m-thick oxide layer. Pattern transfer to the Si layer is made by RIE using $\mathrm{SF}_{6}$ at cryogenic temperature of $-125^{\circ} \mathrm{C}$. In a second step, the Si device layer thickness is adjusted to the desired thickness of $250 \mathrm{~nm}$ by another RIE cryogenic etching step after removal of the photoresist. The third step comprises wet-etching with hydrofluoric acid to remove the buried oxide and supercritical point drying to prevent sticking effects. In the last step, $\mathrm{Cr}$ buffer layer and NiMnGa thin film are deposited as described before. More details on the nanomachining process can be found in Ref. [9].

This fabrication process has been successfully applied to prepare freestanding $\mathrm{NiMnGa} / \mathrm{Si}$ nanoactuators with decreasing lateral widths down to $200 \mathrm{~nm}$. Figure $2 \mathrm{~b}$ shows a SEM micrograph of a $\mathrm{NiMnGa/Si}$ bimorph double-beam with minimal beam width of $200 \mathrm{~nm}$. Due to sputtering onto a nanomachined SOI substrate and the rather low directionality of the sputtering process, deposition of NiMnGa film does not only occur on the top surface but also at the sidewalls. Therefore, additional Argon ion beam etching is performed at a low angle to remove sidewall deposition. The average grain size of the polycrystalline NiMnGa film is about $75 \mathrm{~nm}$ in diameter, whereas the grain size of the NiMnGa/Si bimorph nanoactuators has a larger diameter of up to $200 \mathrm{~nm}$ as can be seen in Fig. 2b.

Figure 2c shows a SEM micrograph of a $\mathrm{NiMnGa} / \mathrm{Si}$ bimorph nanoactuator after removal of sidewall deposition. The layer sequence is clearly visible. The nanoactuator is deflected in out-of plane direction indicating the presence of built-in stress that occurs due to cooling from deposition temperature to room temperature.

As a reference system showing only the bimorph effect, $\mathrm{Ni} / \mathrm{Si}$ bimorph nanoactuators are fabricated having the same layout and following the same fabrication process. In particular, Ni films are deposited at $500{ }^{\circ} \mathrm{C}$ onto a $\mathrm{Cr}$ buffer layer after nanomachining of the SOI substrate.

\section{Results and Discussion}

\section{Electrical Resistance}

Electrical resistance measurements are performed to gain insight into the progress of martensitic phase transformation. This includes the determination of phase transition temperatures and, thus, the evaluation of phase stability. In order to investigate the effect of substrate constraints and to evaluate the impact of the $\mathrm{Si}$ layer on the $\mathrm{NiMnGa} / \mathrm{Si}$ nanoactuator performance three reference systems are considered: (i) $\mathrm{NiMnGa}$ thin films, (ii) $\mathrm{NiMnGa} / \mathrm{Si}$ bimorph actuators with micrometer size, and (iii) $\mathrm{Ni} / \mathrm{Si}$ bimorph nanoactuators. The electrical resistance characteristics of the different samples are determined inside a SEM as a function of electrical power by the four-point method. 
Table 1 Dimensions of $\mathrm{NiMnGa} / \mathrm{Si}$ bimorph nanoactuators and a reference actuator

\begin{tabular}{llll}
\hline Beam width $^{\mathrm{a}} w(\mathrm{~nm})$ & Beam length $l(\mu \mathrm{m})$ & Tip length $l_{\text {tip }}(\mathrm{nm})$ & Thickness $t_{\mathrm{Si}} t_{\mathrm{SMA}}(\mathrm{nm})$ \\
\hline 200 & 8.3 & 300 & $200 / 250$ \\
250 & 15.45 & 450 & $200 / 250$ \\
300 & 20.6 & 600 & $200 / 250$ \\
350 & 25.75 & 750 & $200 / 250$ \\
400 & 24.9 & 900 & $200 / 250$ \\
450 & 22.05 & 1050 & $200 / 250$ \\
2000 & 24 & 4000 & $1000 / 1000$ \\
\hline
\end{tabular}

${ }^{a}$ The gap width in between the beams is designed to be $500 \mathrm{~nm}$

\section{NiMnGa Thin Films}

NiMnGa thin films of $200 \mathrm{~nm}$ and $1 \mu \mathrm{m}$ thickness have been prepared on Si substrates as reference samples. Figure 3 shows electrical resistance characteristics of these films in the temperature range of martensitic phase transformation. Both films exhibit the characteristic anomaly due to martensitic phase transformation as well as a narrow thermal hysteresis of about $1 \mathrm{~K}$. While the courses of electrical resistance are very similar in martensitic state, they differ considerably in the temperature range of phase transformation. Similar to previous experiments on NiMnGa films [10, 11], we find that a decrease in film thickness results in a broadening of the phase transformation regime. Such broadening effect hampers unambiguous determination of phase transformation temperatures. Previous experiments on $\mathrm{NiMnGa}$ thin films also revealed apparent shifts of martensitic transformation temperature being highly dependent on the substrate material and structure $[10,11]$. Using the tangential method, we find a

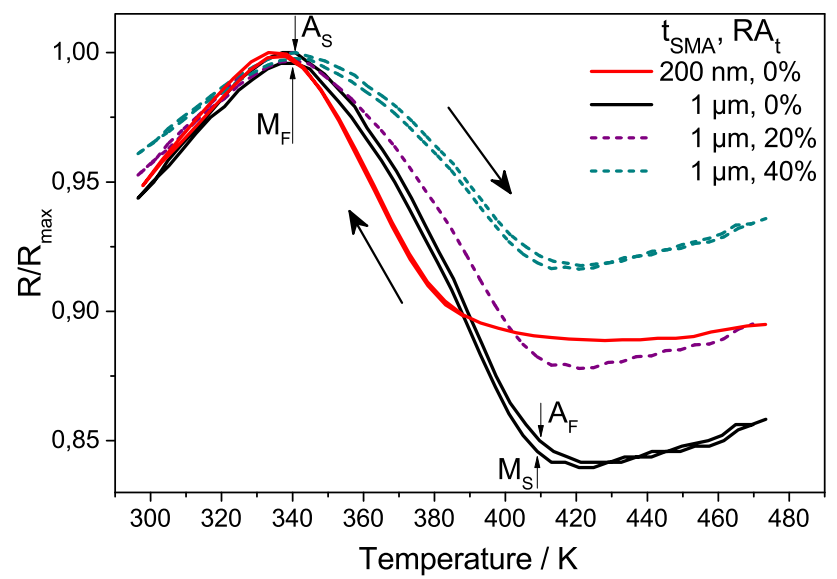

Fig. 3 Normalized electrical resistance characteristics as a function of temperature for a NiMnGa film of $200 \mathrm{~nm}$ and $1 \mu \mathrm{m}$ thickness on a $\mathrm{Si}$ substrate (solid lines). Start and finish temperatures of martensite (M) and austenite (A) $M_{\mathrm{S}, \mathrm{F}}$ and $A_{\mathrm{S}, \mathrm{F}}$ have been determined by the tangential method. Dashed lines have been determined by multiplying the characteristic of the $1 \mu \mathrm{m}$ film with the correction factor $\mathrm{RA}_{t}$ as indicated to illustrate the effect of residual austenite decrease of martensite start temperature when reducing the film thickness from $1 \mu \mathrm{m}$ to $200 \mathrm{~nm}$. However, the temperature of resistance minimum keeps about the same.

Another observation in Fig. 3 is that the change of electrical resistance decreases for decreasing film thickness. This indicates that phase transformation remains incomplete. A possible explanation could be the presence of residual austenite at the substrate to thin film interface. The effect of residual austenite not transforming into martensite even at temperatures well below the martensite start temperature has been observed in several studies on SMA thin films [12-14]. For epitaxially grown NiMnIn films on $\mathrm{Si}$ [12] and $\mathrm{NiMnGa}$ films on $\mathrm{MgO}$ [14], for instance, layer thicknesses of residual austenite at the filmsubstrate interface below $30 \mathrm{~nm}$ were observed. The presence of residual austenite has been attributed to substrate constraints depending on the lattice misfit between austenite and substrate [13]. In polycrystalline films, the amount of residual austenite is expected to be significantly higher, because grain boundaries exert constraints on the formation of the self-accommodated twin microstructure as well as on its reorienting during training [15]. Following these lines, we presume that a non-transforming interface regime between Si substrate and NiMnGa film exists due to high stress levels, which tends to increase for decreasing film thickness. Here, we estimate the fraction of nontransforming austenite by introducing a correction factor $R A_{t}$ based on the maximum change of electrical resistance. Taking the $1-\mu \mathrm{m}$-thick film as a reference, we find that the volume fraction of SMA material contributing to the phase transformation in the $200 \mathrm{~nm}$ thin film is reduced by about $20 \%$ as indicated by the dashed lines in Fig. 3 .

\section{NiMnGa/Si Bimorph Microactuators}

Another set of reference samples for characterization of the $\mathrm{NiMnGa} / \mathrm{Si}$ bimorph nanoactuators are $\mathrm{NiMnGa} / \mathrm{Si}$ microactuators consisting of double beams with lateral dimensions of $2 \mu \mathrm{m}$ and thicknesses of NiMnGa and $\mathrm{Si}$ layer of $1 \mu \mathrm{m}$ (see Table 1). In comparison to the thin film measurements, the characteristics of these samples are 
determined by Joule heating as homogeneous heating has not been possible for the nanoactuators.

Homogeneous heating implies heating of the whole substrate causing thermal expansion of the whole substrate chip. The resulting movements are much bigger than the field of vision in the SEM that is needed to resolve the deflection of the bimorph nanoactuators. In contrast, Joule heating allows for selective heating of a single bimorph actuator and therefore enables deflection measurements with sufficient accuracy. For comparison of data between the different samples, it is essential to determine the temperature profile as a function of applied electrical power. Due to rapid heat transfer to the onset of the double beams, Joule heating results in a temperature gradient along the beams showing the highest values at the beam tip and lowest values close to substrate at the beam onset. As a consequence of this temperature profile, the phase fraction of martensite varies along the beam, thus, all material properties depending on the phase fraction vary along the beam as well. Therefore, any measurement of electrical resistance during Joule heating gives rise to a superposition of different phase states occurring along the beam cantilever. In particular, some sections of the beam may have already transformed to austenite, while other sections may still be in martensitic state.

In order to compare electrical resistivity characteristics determined as a function of electrical heating power, the corresponding temperature profiles along the beams have to be known. Therefore, the stationary heat equation for the $\mathrm{NiMnGa/Si} \mathrm{bimorph} \mathrm{cantilever} \mathrm{beam} \mathrm{is} \mathrm{solved} \mathrm{numerically}$ by approximating the temperature-dependent heat conductivity of the two layers. The heat conductivity of $\mathrm{NiMnGa} k_{\mathrm{NiMnGa}}(T)$ is approximated by the WiedemannFranz law [16] describing the heat conductivity of metals as a function of electrical conductivity $\sigma$

$k_{\mathrm{NiMnGa}}(T)=L_{\mathrm{o}} \cdot \sigma_{\mathrm{NiMnGa}}(T) \cdot T$,

with the proportionality constant $L_{o}=2.45 \times 10^{-8} \frac{\mathrm{W} \Omega}{K^{2}}$ [16]. Following Ref. [17], the thermal conductivity of $\mathrm{Si}$ is approximated by

$k_{\mathrm{Si}}(T)=\frac{5.0105 \times 10^{4} \frac{\mathrm{W}}{\mathrm{m}}}{T}-19.24 \frac{\mathrm{W}}{\mathrm{mK}}$.

Figure 4a shows a series of temperature profiles along the beam $(x-)$ direction for the $\mathrm{NiMnGa} / \mathrm{Si}$ reference microactuator for different values of electrical heating power of $10,12,14$, and $16 \mathrm{~mW}$. These results indicate that very high temperatures occur at the beam tip, while the beam onset is close to room temperature. For the nanoactuators, even larger temperature gradients occur along the beam direction reaching $50 \mathrm{~K} / \mu \mathrm{m}$.

As the simulated temperature distribution is characterized by the maximum temperature at the beam tip for a (a)
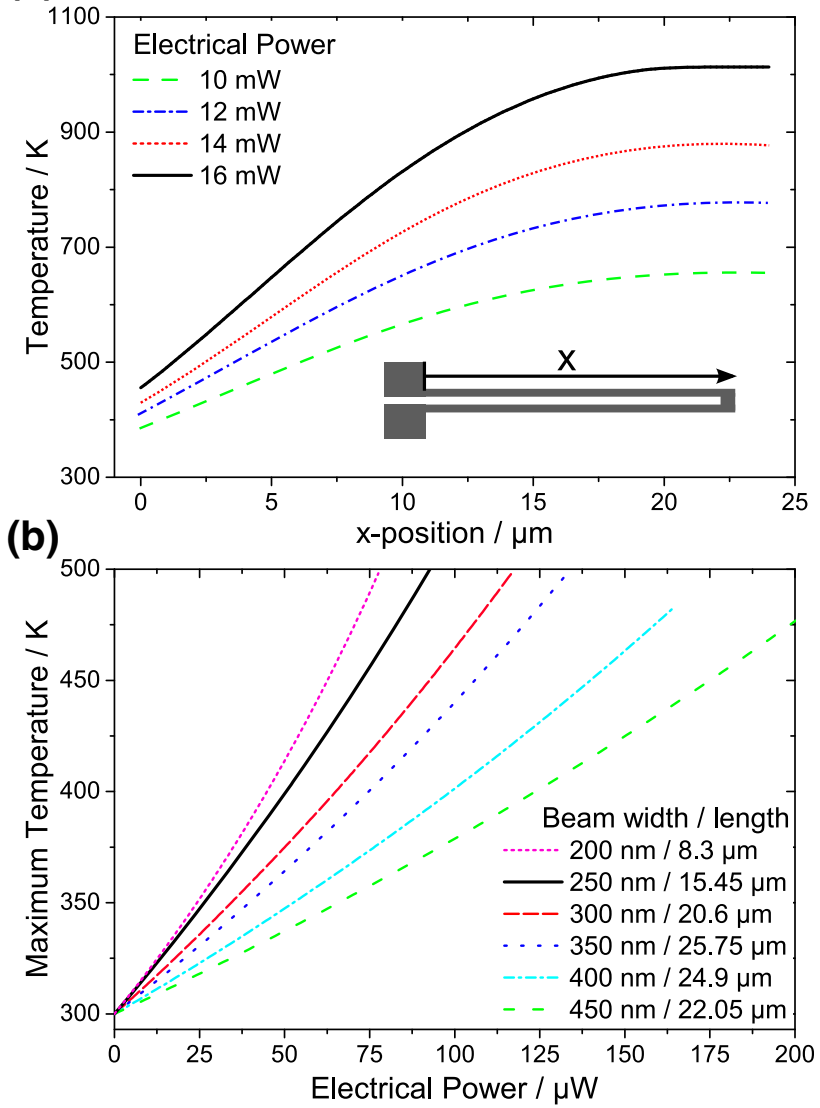

Fig. 4 a Simulated temperature profiles along beam $(x-)$ direction of the $\mathrm{NiMnGa} / \mathrm{Si}$ reference microactuator for different values of heating power as indicated. b Simulated characteristics of maximum temperature at the beam tip as a function of electrical heating power for the beam cantilever geometries of the test samples listed in Table 1

given electrical power $T_{\max }\left(P_{\mathrm{el}}\right)$, the electrical resistance $R\left(P_{\mathrm{el}}\right)$ is plotted versus $T_{\max }$ in the following, in order to compare electrical resistance characteristics of different samples. Figure $4 \mathrm{~b}$ gives an overview of simulated characteristics $T_{\max }\left(P_{\mathrm{el}}\right)$ for the beam cantilever geometries of the investigated test samples.

Figure 5 shows, for instance, corresponding electrical resistance characteristics as a function of $T_{\max }$ for a NiMnGa thin film of $1 \mu \mathrm{m}$ thickness and the $\mathrm{NiMnGa} / \mathrm{Si}$ bimorph microactuator. Both characteristics are very similar, indicating that micromachining has a minor effect on the martensitic transformation. This result also demonstrates that the procedure of converting electrical power to the reference temperature $T_{\max }$ is appropriate. Comparing the resistance characteristics of the reference film for homogenous and Joule heating in Figs. 3 and 5, respectively, a smaller change of resistance occurs in the case of a temperature gradient.

The bimorph microactuator exhibits a smaller change of resistance compared to the reference film indicating a 
(a)

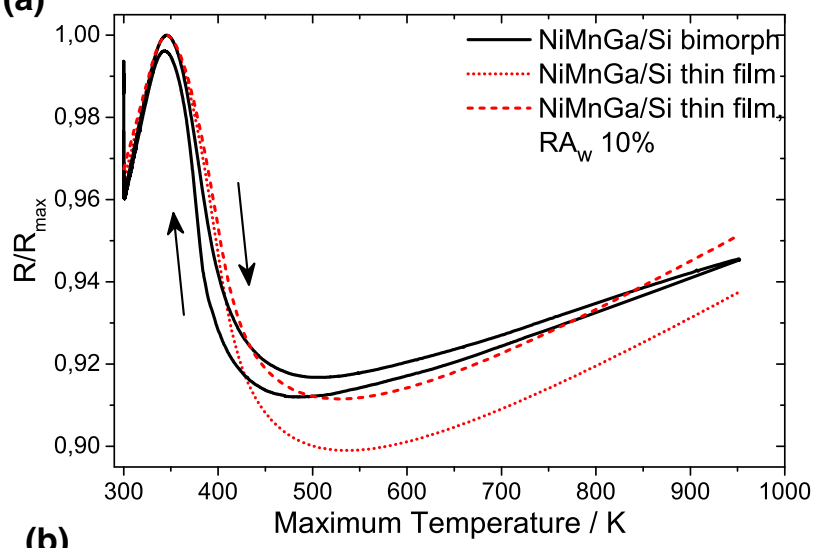

(b)

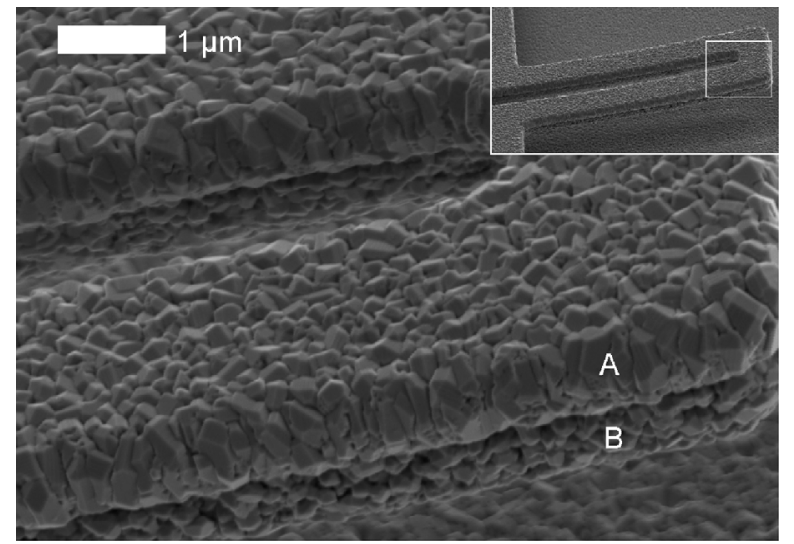

Fig. 5 a Normalized electrical resistance characteristics as a function of maximum temperature of a NiMnGa thin film of $1 \mu \mathrm{m}$ thickness and a NiMnGa/Si bimorph microactuator with beam width, thickness, and length of 2, 2, and $24 \mu \mathrm{m}$, respectively. b SEM micrograph of a $\mathrm{NiMnGa/Si}$ bimorph microactuator showing that the grain size in the NiMnGa layer is in the range of 50-100 nm (A). Sidewall deposition on the Si layer (B) is clearly visible

reduced volume fraction of transforming SMA material. This reduction is approximated by a width-dependent correction factor $R A_{\mathrm{w}}$ similar to the thickness-dependent effect discussed before.

\section{Ni/Si Bimorph Nanoactuators}

The third set of reference samples are $\mathrm{Ni} / \mathrm{Si}$ bimorph nanoactuators. Electrical resistance measurements are intended to elucidate possible effects of nanofabrication on electrical conductivity as these samples do not show a martensitic transformation. Figure $6 \mathrm{a}$ shows electrical resistance characteristics versus maximum temperature $T_{\max }$ of a $\mathrm{Ni}$ film of $200 \mathrm{~nm}$ thickness deposited on a $\mathrm{Si}$ substrate and of a Ni/Si bimorph nanoactuator. The electrical resistance characteristic of the $\mathrm{Ni}$ film has been determined from literature data as a function of temperature $R(T)$ [18] and $T_{\max }$ has been determined according to the procedure discussed in the previous section. The Ni thin film shows a characteristic change of slope, which is commonly ascribed to the Curie temperature [18]. The corresponding $\mathrm{Ni} / \mathrm{Si}$ bimorph nanoactuator shows a similar kink; however, the corresponding critical temperature is shifted to lower values by more than $165 \mathrm{~K}$. A size-dependent shift of Curie temperature in Ni samples has been reported before; however, critical dimensions of $\mathrm{Ni}$ structures have been much lower in the order of $2 \mathrm{~nm}$ [19]. A more likely explanation of the observed temperature shift is a size-dependence of thermal conductivity in the Si substrate. Due to the very low doping concentration in the $\mathrm{Si}$ substrate, heat is mainly conducted by phonons having a mean free path in the order of $250 \mathrm{~nm}$ at room temperature [20]. Thus, reducing the dimensions (thickness and width) of the $\mathrm{Si}$ substrate down to $250 \mathrm{~nm}$ leads to a decrease in thermal conductivity $[21,22]$. Here, this effect is taken into account by introducing a scaling parameter $\mathrm{F}$ describing the ratio of the thermal conductivities of bulk $k_{\mathrm{Si}}^{\text {bulk }}(T)$ and nanostructured Si $k_{\mathrm{Si}}^{\mathrm{nano}}(T)$

$k_{\mathrm{Si}}^{\text {nano }}(T)=F \cdot k_{\mathrm{Si}}^{\text {bulk }}(T)$.

As shown in Fig. 6b, the critical temperature of the kink can be rescaled by the scaling parameter.

For $F=0.41$, the characteristics of Ni thin film and Ni/ Si bimorph nanoactuator almost coincide showing a similar change of slope at the same critical temperature. Therefore, we conclude that the size-dependence of thermal conductivity in the silicon substrate has to be taken into account in the following, when investigating possible size-dependent effects of martensitic transformation in the $\mathrm{NiMnGa} / \mathrm{Si}$ bimorph nanoactuators. Similarly, individual scaling parameters are determined for the other $\mathrm{Ni} / \mathrm{Si}$ bimorph actuators; see Table 2.

\section{NiMnGa/Si Bimorph Nanoactuators}

Figure 7 shows normalized electrical resistance characteristics of the $\mathrm{NiMnGa} / \mathrm{Si}$ bimorph nanoactuators listed in Table 1. For comparison, the electrical resistance characteristics of the corresponding NiMnGa reference film of $200 \mathrm{~nm}$ thickness and of the NiMnGa/Si microactuator are included. These characteristics have been corrected for reduced volume fraction of transforming SMA material by the correction factors $R A_{t}$ and $R A_{\mathrm{w}}$ taking into account the beam thickness and width dependences, respectively. In addition, the size-dependence of thermal conductivity of the $\mathrm{Si}$ layer is taken into account by the form factors $F$ determined from electrical characteristics of the corresponding $\mathrm{Ni} / \mathrm{Si}$ bimorph actuators having the same dimensions of the Si layer. The obtained values of correction factors $R A_{\mathrm{w}}$ and $F$ for the different nanoactuators and reference microactuator are summarized in Table 2. 


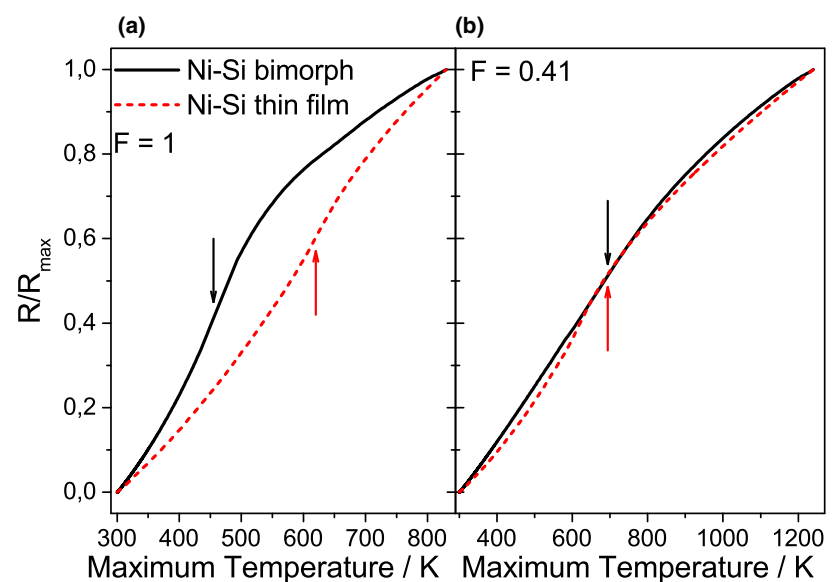

Fig. 6 Normalized electrical resistance characteristics as a function of maximum temperature of a Ni thin film of $200 \mathrm{~nm}$ thickness and a $\mathrm{Ni} / \mathrm{Si}$ bimorph nanoactuator with beam width, thickness, and length of 250,450 , and $6450 \mathrm{~nm}$, respectively. The characteristic temperatures for the kink are indicated by arrows. a Original data without correction, b the characteristic of the $\mathrm{Ni} / \mathrm{Si}$ bimorph nanoactuator is modified by taking into account the size-dependent reduction of thermal conductivity of the Si layer by the form factor $F=0.41$

Table 2 Temperature shifts $\Delta T$ of austenite start temperature of $\mathrm{NiMnGa/Si} \mathrm{bimorph} \mathrm{nanoactuators} \mathrm{with} \mathrm{respect} \mathrm{to} \mathrm{reference} \mathrm{film}$

\begin{tabular}{llll}
\hline$w / l / t(\mu \mathrm{m})$ & $R A_{\mathrm{w}}(\%)$ & $F$ & $\Delta T(\mathrm{~K})$ \\
\hline 0.2 / 8.3 / 0.45 & 13 & - & 40 \\
$0.25 / 15.45 / 0.45$ & 32 & 0.41 & 20 \\
0.3 / 20.6 / 0.45 & 34 & 0.55 & 21 \\
0.35 / 25.75 / 0.45 & 32.5 & 0.62 & 24 \\
0.4 / 24.9 / 0.45 & 35 & - & 23 \\
0.45 / 22.05 / 0.45 & 34 & 0.63 & 23 \\
$2.0 / 24.0 / 2.0$ & - & - & 0 \\
\hline
\end{tabular}

The dimensions of nanoactuators and correction factors are indicated $w / l / t$ - beam width, length, and total beam thickness $\left(t=t_{\mathrm{SMA}}+t_{\mathrm{Si}}\right)$, respectively; $R A_{w}$-correction factor for the beam width-dependent reduced volume fraction of transforming SMA material; $F$-form factor for the size-dependent thermal conductivity of the Si layer; $\Delta T$ - shift of austenite start temperature of bimorph nanoactuators with respect to reference film

The NiMnGa/Si bimorph microactuator and reference film exhibit a very similar course of normalized electrical resistance. In particular, the electrical resistance maxima occur at the same temperatures indicating that phase transformation temperatures $M_{\mathrm{F}}$ and $A_{\mathrm{S}}$ do not change due to microfabrication. Comparing the normalized electrical resistance characteristics of the different bimorph nanoactuators reveals a significant dependence of the temperatures of resistance maxima on the beam widths. While the resistance maximum of the microactuator compares to the reference film, the resistance maxima of the nanoactuators shift to lower temperatures by about $20-24 \mathrm{~K}$ for beam

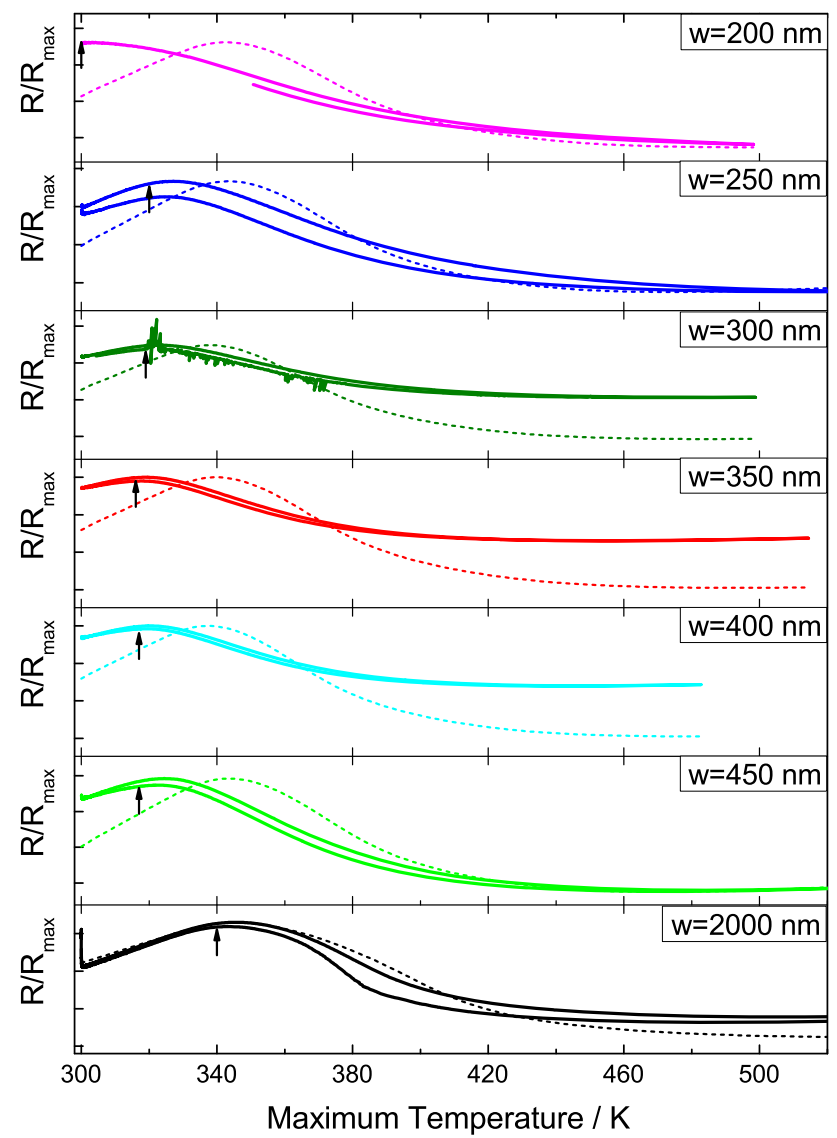

Fig. 7 Normalized electrical resistance characteristics as a function of maximum temperature of $\mathrm{NiMnGa} / \mathrm{Si}$ bimorph nanoactuators (solid lines) of different beam widths $w$ as indicated and of a NiMnGa reference film of $200 \mathrm{~nm}$ thickness (dashed lines). The dimensions of the nanoactuators and correction factors are listed in Table 2

widths of $0.25-0.45 \mu \mathrm{m}$ reaching about $40 \mathrm{~K}$ for the smallest beam width of $200 \mathrm{~nm}$. The results on temperature shifts $\Delta T$ are listed in Table 2.

The observed temperature shifts cannot be explained by a heating effect of the electron beam in the SEM as the heating power at $5 \mathrm{kV}$ is negligible [23]. The observed width-dependent decrease of phase transformation temperatures $M_{\mathrm{F}}$ and $A_{\mathrm{S}}$ rather indicates that martensite becomes less stable, when the lateral dimensions approach the grain size and surface effects become dominant. The effect of martensite destabilization is analog to previously observed thicknessdependent shifts of phase transformation temperatures in nanoscale SMA thin films [24]. Compression experiments on SMA nanopillars also reveal the same trend [25].

\section{Mechanical Performance}

\section{NiMnGa/Si Bimorph Nanoactuators}

Simultaneously to the electrical resistance measurements, the out-of-plane deflection of the nanoactuator front is 
determined in situ inside a SEM by recording video sequences and performing digital image analysis. For this purpose, the substrate is mounted at an angle of $85^{\circ}$ with respect to the detector. Any movement of the beam onset is subtracted in order to obtain net deflections. Figure 8 shows the deflection characteristics of a $\mathrm{NiMnGa} / \mathrm{Si}$ bimorph nanoactuator with $250 \mathrm{~nm}$ beam width.

While the electrical resistance characteristics show the typical features of a martensitic phase transformation, only a minor change of slope is observed in the deflection characteristic. Starting from an initial out-of-plane bent state, the deflection decreases for increasing electrical power. The tip temperature span is between room temperature RT and about $520^{\circ} \mathrm{C}$, resulting in a maximum deflection of approximately $1.25 \mu \mathrm{m}$, which is about $8 \%$ of the total beam length. This result indicates that the thermal bimorph effect dominates the deflection performance.

In order to discriminate between the effects of differential thermal expansion and SME, a finite element (FE) model for continuum mechanical analysis including heat transfer and several extensions have been set up. For this purpose, the commercial software package COMSOL Multiphysics is used, particularly the Non-linear Solid Mechanics and the Heat Transfer module. For the smallest feature size, the maximum mesh element size was set to $30 \mathrm{~nm}$ to achieve convergence while minimizing the computational effort. In its basic version (model \#1), fixed values for the thermal expansion coefficients and Young's moduli of Si and NiMnGa are considered, respectively. The corresponding deflection characteristic is shown in Fig. 8 as a dashed line. The overall deflection agrees very well with the experimental result indicating that the thermal bimorph effect indeed explains the main deflection performance. However, the model does not describe the slope of the deflection. In a first extension (model \#2), different thermal expansion coefficients and stiffnesses in austenitic and martensitic state are taken into account. For this purpose, a variable for the martensitic phase fraction $\xi_{\mathrm{m}}(T)$ is introduced that approximates the phase transformation by a temperature-dependent exponential step function $\xi_{\mathrm{M}}(T)$ that varies between 1 (martensitic state) and zero (austenitic phase). In the phase transformation regime, the temperaturedependent material properties are approximated by the rule of mixture. In the case of the thermal expansion coefficient of $\mathrm{NiMnGa}$, we thus obtain

$\alpha(T)=\left(1-\xi_{\mathrm{M}}(T)\right) \cdot \alpha_{\mathrm{A}}+\xi_{\mathrm{M}}(T) \cdot \alpha_{\mathrm{M}}$,

with $\alpha_{M} / \alpha_{A}$ being the thermal expansion coefficients of martensite/austenite. The corresponding deflection characteristic is depicted in Fig. 8 as well. In this case, good agreement is obtained in the first part of the deflection characteristic at low temperatures while for larger temperatures the model characteristic 2 approaches model characteristic 1 .

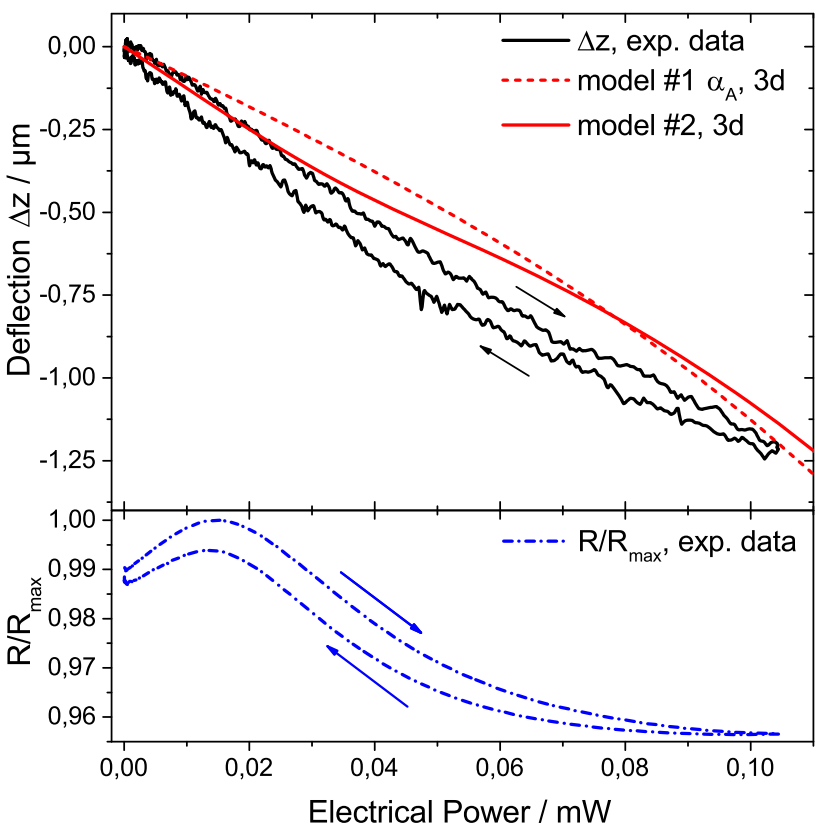

Fig. 8 Experimental deflection and normalized electrical resistance characteristics as a function of electrical heating power of a $\mathrm{NiMnGa} /$ Si bimorph actuator of width, thickness, and length of $250 \mathrm{~nm}$, $450 \mathrm{~nm}$, and $15.45 \mu \mathrm{m}$, respectively. The simulated deflection behaviors are based on two different models as explained in the text

\section{Evaluation of Shape Memory Effect}

The presented results demonstrate that the mechanical performance can be well described by a simple model including only the thermal bimorph effect, while the SME plays a minor role upon Joule heating even though martensitic transformation is clearly observed in the electrical resistance performance. This raises the question on the role of the SME in the bimorph nanoactuators and how it could be optimized. In order to answer these questions, a second model extension is considered (model \#3) that takes the thermal SME into account. In particular, the effects of temperature gradient due to Joule heating and of substrate constraints will be evaluated.

Model \#3 approximates the quasi-plastic stress-strain behavior in martensitic state and elastic response in austenitic state as follows:

$\sigma_{M}(\varepsilon)= \begin{cases}\varepsilon E_{1} & \varepsilon<\varepsilon_{1}=0.001 \\ \varepsilon E_{2} & \varepsilon_{1} \leq \varepsilon \leq \varepsilon_{2} \\ \varepsilon E_{1} & \varepsilon>\varepsilon_{2}=0.06\end{cases}$

$\sigma_{\mathrm{A}}(\varepsilon)=\varepsilon E_{1}$.

Here, the stress-strain characteristic of martensite is defined in sections by three strain regimes. In order to keep the model as simple as possible, the same value of Young 's modulus is used for the initial elastic regimes in austenite and in martensite. In martensitic state, in the range of strains between $\varepsilon_{1}$ and $\varepsilon_{2}$, the quasi-plastic stress-strain 
behavior is described by a low stiffness parameter $E_{2}$. In the phase transformation regime, the stress is approximated by the rule of mixture:

$\sigma(T, \varepsilon)=\left(1-\xi_{\mathrm{M}}(T)\right) \cdot \sigma_{\mathrm{A}}(\varepsilon)+\xi_{\mathrm{M}}(T) \cdot \sigma_{\mathrm{M}}(\varepsilon)$.

Literature data on Young's modulus of NiMnGa are broadly scattered reflecting different fabrication technologies. In the following, we assume $E_{1}=100 \mathrm{GPa}$, which is in line with tensile tests on micrometer-sized NiMnGa films [26-30], and $E_{2}=100 \mathrm{MPa}$. The material parameters used in the different models for the mechanical performance of the $\mathrm{NiMnGa} / \mathrm{Si}$ bimorph nanoactuators are summarized in Table 3.

By using models \#1-3, we evaluate the effects of thermal expansion and stress-strain behavior on the deflection during cooling of NiMnGa-Si bimorph actuators after sputter deposition at temperature $T=500{ }^{\circ} \mathrm{C}$. Thereby, we assume that cooling occurs under quasi-stationary conditions, i.e., the bimorph actuators are considered to exhibit a homogeneous temperature distribution in this case. Corresponding temperature-dependent deflection characteristics are shown in Fig. 9 for bimorph actuators with SMA layer thicknesses $t_{\mathrm{SMA}}$ of 90,200 , and $300 \mathrm{~nm}$. Si layer thickness $t_{\mathrm{Si}}(250 \mathrm{~nm})$ and beam length $(15.45 \mu \mathrm{m})$ are kept constant.

In initial condition at $500{ }^{\circ} \mathrm{C}$, the bimorph actuator is assumed to be in planar state. Upon cooling, differential thermal contraction causes out-of-plane bending. Since the thermal expansion coefficient for $\mathrm{NiMnGa}$ is roughly one order of magnitude larger than for $\mathrm{Si}$, the actuator deflects upwards for decreasing temperature. With further cooling to the phase transformation regime, two additional effects occur due to the phase-dependent change of thermal expansion coefficient $(\Delta \alpha$-effect) and stiffness (SME). Figure 9 reveals how the contributions of the different effects to the actuator deflection depend on the SMA layer thickness $t_{S M A}$.

For SMA layer thickness of $300 \mathrm{~nm}$, the simulated actuator deflection exhibits a sharp increase after reaching the $M_{S}$ temperature and then levels off upon cooling below $M_{\mathrm{F}}$ temperature. This behavior can be understood by comparing the simulated deflections based on model \#1 using a constant thermal expansion coefficient of either austenite $\alpha_{A}$ or martensite $\alpha_{M}$ giving the upper and lower limit for the out-of-plane deflection, respectively. Thus, the simulated deflection mainly reflects the $\Delta \alpha$-effect, while the SME seems to be absent. This can be explained by the low average strain for SMA/Si layer thickness ratios larger than one, which is below the lower limit $\varepsilon_{1}$ for onset of quasi-plastic deformation. On the other hand, the $\Delta \alpha$-effect leads to a significant stress increase and corresponding increase in out-of plane deflection.

For smaller SMA layer thicknesses, the average strain increases as the SMA volume undergoing quasi-plastic
Table 3 Material parameters for modeling of thermal expansion and stress-strain dependence in models \#1-3 as described in the text

\begin{tabular}{|c|c|c|c|}
\hline & Model \#1 & Model \#2 & Model \#3 \\
\hline \multicolumn{4}{|c|}{ NiMnGa } \\
\hline$\alpha$ & $\alpha_{M}$ or $\alpha_{A}$ & $\alpha(T)($ Eq. 4$)$ & $\alpha(T)$ (Eq. 4) \\
\hline$\sigma(\varepsilon)$ & $\sigma(\varepsilon)=\varepsilon E_{1}$ & $\sigma(\varepsilon)=\varepsilon E_{1}$ & $\sigma(T, \varepsilon)($ Eq. 7) \\
\hline$\kappa$ & \multicolumn{3}{|c|}{$k_{N i M n G a}(T)($ Eq. 1) } \\
\hline$\rho$ & \multicolumn{3}{|c|}{$\rho(T)=\left(1-\xi_{M}(T)\right) \cdot \rho_{A}(T)+\xi_{M}(T) \cdot \rho_{M}(T)$} \\
\hline \multicolumn{4}{|l|}{$\mathrm{Si}$} \\
\hline$\alpha$ & \multicolumn{3}{|l|}{$\alpha_{\mathrm{Si}}(T)$} \\
\hline E & \multicolumn{3}{|c|}{$E_{\mathrm{Si}}$} \\
\hline$\kappa$ & \multicolumn{3}{|c|}{$k_{\mathrm{Si}}^{\mathrm{nano}}(T)($ Eqs. 2,3$)$} \\
\hline$\rho$ & \multicolumn{3}{|c|}{$50 \Omega / \mathrm{cm}$} \\
\hline
\end{tabular}

Thermal expansion coefficients of NiMnGa in martensitic/austenitic state: $\alpha_{\mathrm{M}}=33 \times 10^{-6} \mathrm{~K}^{-1} / \alpha_{\mathrm{A}}=23 \times 10^{-6} \mathrm{~K}^{-1} \quad[31,32]$; the thermal expansion coefficient of $\mathrm{Si} \alpha_{\mathrm{Si}}(T)$ is given by a polynomial of fourth-order taken from [33]; Young's modulus of Si: $E_{\mathrm{Si}}=169 \mathrm{GPa}$ [34]; electrical resistivity of NiMnGa in martensite/austenite is taken from the measurements on NiMnGa thin films of $200 \mathrm{~nm}$ thickness; electrical resistivity of $\mathrm{Si}$ has been provided by the wafer supplier

deformation increases and, thus, stress release gains significance. Therefore, the simulated actuator deflections for SMA layer thicknesses of 200 and $90 \mathrm{~nm}$ exhibit a smaller increase after reaching the $M_{\mathrm{S}}$ temperature and do not level off upon further cooling. Instead, after reaching maximum deflection at temperature $T_{\mathrm{P}}$, indicated by arrows in Fig. 9, the deflection decreases again until the $M_{\mathrm{F}}$ temperature is reached. This indicates that stress release due to the SME is

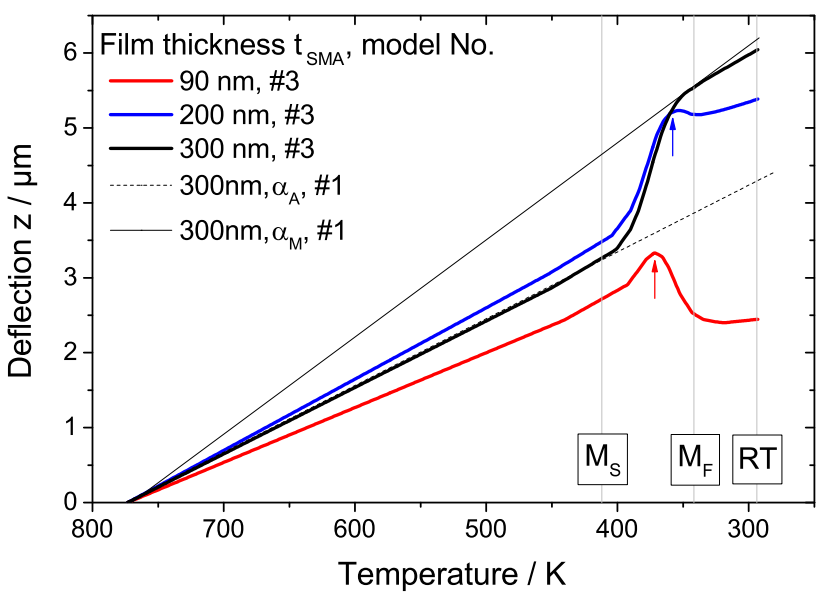

Fig. 9 Simulated temperature-dependent deflections in out-of-plane direction upon cooling for $\mathrm{NiMnGa} / \mathrm{Si}$ bimorph actuators with SMA layer thicknesses $t_{\mathrm{SMA}}$ as indicated. Si layer thickness and beam length are $250 \mathrm{~nm}$ and $15.45 \mu \mathrm{m}$, respectively. The temperature span is between the deposition temperature of $500{ }^{\circ} \mathrm{C}$ and room temperature RT. For $t_{\mathrm{SMA}}>300 \mathrm{~nm}$, the deflection is dominated by the $\Delta \alpha$ effect; for $t_{\mathrm{SMA}}<300 \mathrm{~nm}$, a change of deflection due to martensitic transition is observed. The characteristic peak temperatures $T_{\mathrm{P}}$ are indicated by arrows 
effectively counteracting the $\Delta \alpha$-effect and differential thermal compression.

From these observations it is clear that the relative contributions of the different effects depend on the temperature spans. Since the bimorph nanoactuators do not allow for homogeneous temperature control, the next step is to clarify, how these considerations change when applying Joule heating. The temperature profiles induced by Joule heating in the $\mathrm{NiMnGa} / \mathrm{Si}$ bimorph actuators have been discussed before (Fig. 4). In the experiment presented in Fig. 8, the tip temperature span is between RT and about $520{ }^{\circ} \mathrm{C}$. In this case, the simulated maximum deflection due to the thermal bimorph and $\Delta \alpha$-effect is about $1.25 \mu \mathrm{m}$, which is smaller compared to the homogeneous temperature change between $500{ }^{\circ} \mathrm{C}$ and RT (Fig. 9) as expected. Thereby, we assume that our simulations on the deflection during cooling are valid for the deflection upon heating, which follows from the agreement of simulated and experimental deflections in Fig. 8. The simulated change of deflection due to the effect of martensitic transformation obtained by model \#3 is only about $60 \mathrm{~nm}$. Thus, we conclude that the large temperature gradient induced by Joule heating in the bimorph nanoactuators leads to a significant decrease of the contribution of the SME.

Besides the influence of temperature gradient, also the substrate constraints have to be considered. Any change of out-of-plane deflection causes a change of stress. In particular, maximum stress and stress gradients occur at the interface between NiMnGa film and $\mathrm{Si}$ substrate. If the stress level exceeds a critical limit, plastic deformation is likely to occur, which reduces the fraction of SMA material contributing to the SME. In the following, we assume an upper critical stress value of $500 \mathrm{MPa}$. On the other hand, regions of low stress occurring close to the surface of the $\mathrm{NiMnGa}$ film may not exceed the limit for quasi-plastic deformation and thus do not contribute to the SME as well. Here, we assume that the lower stress limit is $100 \mathrm{MPa}$. Taking these limits into account, we estimate the fraction of SMA material contributing to the SME by calculating the stress profile along thickness direction of the bimorph actuators. Thereby, only those regions are considered to contribute to the SME that keep in the range of lower and upper stress limit. This approach may underestimate the fraction of non-contributing material, as additional effects such as creep occurring at high deposition temperatures may also induce stress relaxation $[35,36]$. A typical stress profile of a $\mathrm{NiMnGa} / \mathrm{Si}$ bimorph actuator along thickness direction is shown in the Appendix.

Figure 10a shows the volume fraction of SMA material contributing to the SME as a function of SMA film thickness for a fixed layer thickness of Si of $250 \mathrm{~nm}$. For SMA film thicknesses larger than $300 \mathrm{~nm}$, material fractions above the lower and upper stress limit remain almost unchanged. In this case, the fraction of SMA material exceeding the lower stress limit is about $42 \%$, while the fraction exceeding the upper limit is about $3.2 \%$ allowing to estimate the fraction contributing to the SME to be about $39 \%$. For SMA film thicknesses below $200 \mathrm{~nm}$, material fractions above the lower and upper stress limit strongly increase. In particular, the fraction of SMA material exceeding the lower limit reaches $100 \%$ below $100 \mathrm{~nm}$ and the upper limit when the film thickness approaches zero. Thus, the fraction contributing to the SME (Fig. 10a, green line), reaches a maximum of nearly $80 \%$ for a SMA film thickness of about $90 \mathrm{~nm}$.

Figure 10b shows the simulated actuation stroke of $\mathrm{NiMnGa/Si} \mathrm{bimorph} \mathrm{actuators} \mathrm{as} \mathrm{a} \mathrm{function} \mathrm{of} \mathrm{SMA} \mathrm{film}$ thicknesses for different temperature spans upon heating at room temperature. The thickness-dependent contributions of
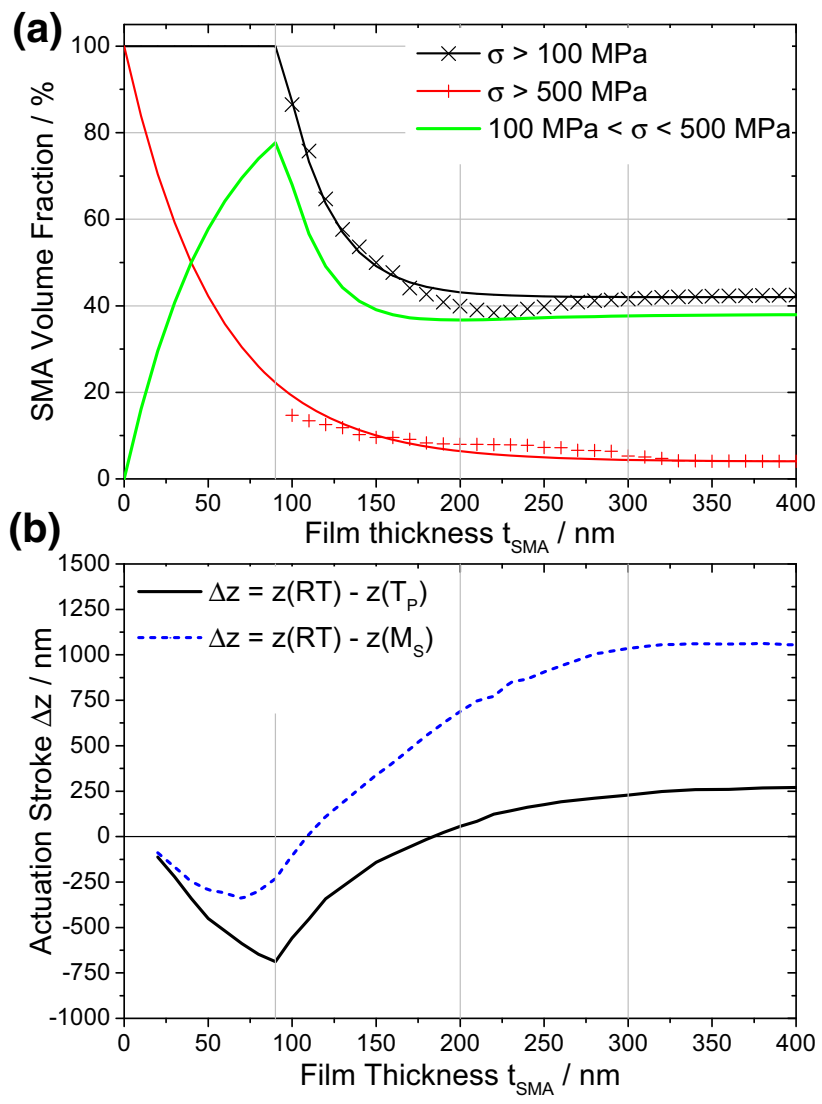

Fig. 10 a Simulated volume fraction of NiMnGa material staying above the assumed limit for quasi-plastic deformation of $100 \mathrm{MPa}$ (black) and above the assumed limit for onset of plastic deformation of $500 \mathrm{MPa}(\mathrm{red})$ as a function of SMA film thickness. Solid lines are fit curves to the FEM simulation data plotted as symbols. The volume fraction in the intermediate stress range (green line) represents the SMA material contributing to the SME. b Simulated actuation stroke as function of SMA film thickness for different temperature spans upon heating at room temperature. The deflection values are taken from Fig. 9 and corrected by the fraction of SMA material contributing to the SME. The Si layer thickness is $250 \mathrm{~nm}$ 
bimorph effect, $\Delta \alpha$-effect, and effect of martensitic transformation are considered (model \#3), and the results are corrected by the fraction of SMA material contributing to the SME. Two thickness regimes may be distinguished reflecting the counteraction of $\Delta \alpha$-effect and SME. For SMA film thicknesses above $200 \mathrm{~nm}$ the stroke is positive not depending on the temperature span. In this case, the $\Delta \alpha$ effect dominates. Consequently, by heating the bimorph above room temperature, the deflection will decrease. For SMA film thicknesses below $200 \mathrm{~nm}$, however, the actuation stroke becomes negative, which refers to a lower beam deflection at room temperature compared to the given deflections at temperatures $M_{\mathrm{S} / \mathrm{F}}$. In this case, the stress relaxation associated with the martensitic transformation is clearly observed. The corresponding optimum thickness revealing maximum negative stroke is about $90 \mathrm{~nm}$. At this film thickness, the estimated fraction of SMA material contributing to the SME exhibits a maximum (Fig. 10a), which enhances the stress relaxation effect. The corresponding maximum negative actuation stroke is in the order of $700 \mathrm{~nm}$ (i.e., $4.5 \%$ of beam length) for the temperature span between RT and peak temperature $T_{\mathrm{P}}$. For larger temperature spans, however, the maximum stroke decreases and eventually becomes positive again due to the increasing $\Delta \alpha$ effect and conventional bimorph effect.

\section{Conclusions}

The investigation of nanoscale SMA actuators relies on a fabrication process with high precision and minimum processing-induced damage. In this work, freestanding functional $\mathrm{NiMnGa} / \mathrm{Si}$ bimorph cantilever structures are fabricated by a process flow that comprises $\mathrm{Si}$ nanomachining followed by magnetron sputtering of a $\mathrm{NiMnGa}$ thin film on an intermediate Cr buffer layer. The combination of widely used Si technology and SMA films opens up a breadth of applications, e.g., in the field of Si photonics and bio technology. Besides structural functionality, $\mathrm{Si}$ is used here for elastic resetting.

However, we demonstrate that the overall behavior of the bimorph nanoactuators is greatly influenced by the $\mathrm{Si}$ substrate. In particular, electrical resistance measurements suggest the presence of a non-transforming layer at the SMA/Si interface, which has also been found in previous studies. Here, we introduce a correction factor for the fraction of residual austenite to match the course of electrical resistance of SMA/Si bimorph actuators in the phase transformation regime with measurements of a reference SMA film. We find that the fraction of non-transforming SMA material increases for decreasing lateral size, which supports the assumption that the non-transforming layer at the interface has a certain thickness. By comparing electrical resistance characteristics of $\mathrm{NiMnGa} / \mathrm{Si}$ bimorph actuators with decreasing lateral size, we find a decrease of transformation temperatures reaching about $40 \mathrm{~K}$ for beam widths of $200 \mathrm{~nm}$.

The present investigations are hampered by the large temperature gradients forming along the bimorph cantilevers upon Joule heating. This effect is even enhanced by a size-dependent decrease of thermal conductivity in the $\mathrm{Si}$ layer. The large temperature gradients observed here lead to a smearing of the phase distribution along the bimorph cantilevers causing a negligible contribution of the SME to the deflection characteristics.

Therefore, the conditions for an optimum use of the SME in SMA/Si bimorph cantilever structures are evaluated by FEM simulations for the case of homogeneous heating. In the present bimorph system, a competition between SME and differential thermal length change as well as phase-dependent change of thermal expansion coefficient $(\Delta \alpha$-effect) occurs, which reduces the overall deflection. A maximum contribution of SME to the bimorph deflection is expected upon heating at room temperature for a SMA/Si thickness ratio of $90 / 250 \mathrm{~nm}$. For the investigated thickness ratio of $200 / 250 \mathrm{~nm}$, however, the $\Delta \alpha$-effect compensates or even outperforms the SME depending on the heating temperature. In order to improve the maximum displacement in SMA/Si bimorph nanoactuators, a combined use of SME and $\Delta \alpha$-effect in mutual support is desirable. Future research and developments could achieve this performance either by attaching a pre-strained SMA film on the substrate or by depositing the SMA film on a pre-strained substrate.

Acknowledgments This work is supported by the Karlsruhe Nano Micro Facility (KNMF), a Helmholtz Research Infrastructure at Karlsruhe Institute of Technology (KIT). VC is grateful to Helmholtz Society for Helmholtz International Fellow Award. The funding by MAT2014-56116-C4-3-4-R (MINECO, Spain) is acknowledged.

\section{Appendix}

Figure 11 shows simulated profiles of tensile stress in a $\mathrm{NiMnGa} / \mathrm{Si}$ bimorph actuator along the thickness (z-) direction for different temperatures without taking into account stress relaxation due to SME (model \#2).

For onset of quasi-plastic deformation, we assume a stress limit of $\sigma_{c l}=100 \mathrm{MPa}$ and for the critical limit of plastic deformation, we assume an upper critical stress value of $500 \mathrm{MPa}$. The fraction of NiMnGa material in the range $\sigma_{\mathrm{c} 1}<\sigma<\sigma_{\mathrm{c} 2}$ is highlighted in yellow. The fraction of NiMnGa exceeding $\sigma_{\mathrm{c} 2}$ is about $5 \%$ at room temperature (highlighted in red). Referring to the electrical resistance measurements, the fraction of non-transforming material $R A_{\mathrm{w}}$ in $\mathrm{NiMnGa} / \mathrm{Si}$ bimorph actuators has been 
(a)
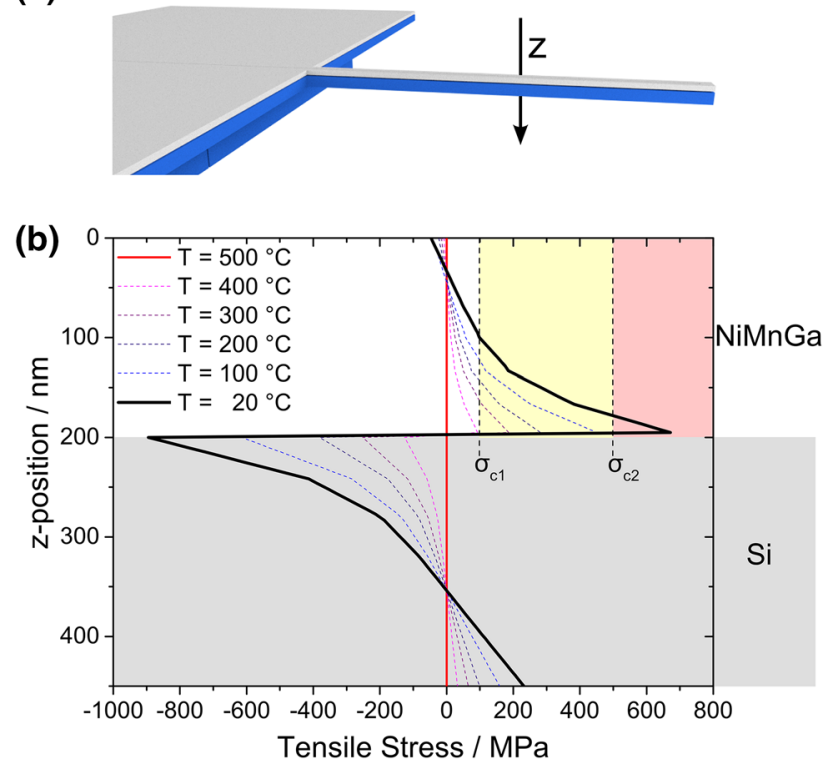

Fig. 11 a Schematic of a SMA/Si bimorph actuator. The $z$-direction is indicated by arrow. b Simulated profiles of tensile stress in a $\mathrm{NiMnGa} / \mathrm{Si}$ bimorph actuator of width, thickness, and length of $250 \mathrm{~nm}, 450 \mathrm{~nm}$, and $15.45 \mu \mathrm{m}$, respectively

approximated to be of the order of $30 \%$. Therefore, the chosen value of $500 \mathrm{MPa}$ most likely represents an underestimation of the actual plastic deformation limit. Based on this consideration, we estimate that about half of the total NiMnGa volume may contribute to the SME at room temperature for the present $\mathrm{NiMnGa} / \mathrm{Si}$ bimorph actuator.

\section{References}

1. Bhattacharya K, James RD (2005) The material is the machine. Science 53:307. http://dx.doi.org/10.1126/science.1100892

2. Sozinov A, Lanska N, Soroka A, Zou W (2013) $12 \%$ magnetic field-induced strain in Ni-Mn-Ga-based non-modulated martensite. Appl Phys Lett 102:021902. doi:10.1063/1.4775677

3. Lázpita P, Rojo G, Gutiérrez J, Barandiaran JM, O’Handley RC (2007) Correlation between magnetization and deformation in a NiMnGa shape memory alloy polycrystalline ribbon. Sens Lett 5(1):65-68. http://dx.doi.org/10.1166/sl.2007.033

4. Chmielus M, Zhang XX, Witherspoon C, Dunand DC, Müllner P (2009) Giant magnetic-field-induced strains in polycrystalline NiMn-Ga foams. Nat Mater 8(13):863-866. doi:10.1038/NMAT2527

5. Shaw GA, Stone DS, Johnson AD, Ellis AB, Crone WC (2003) Shape memory effect in nanoindentation of nickel-titanium thin films. Appl Phys Lett 83:257. doi:10.1063/1.1591235

6. Frick CP, Lang TW, Spark K, Gall K (2006) Stress-induced martensitic transformations and shape memory at nanometer scales. Acta Mater 54:2223-2234. http://dx.doi.org/10.1016/j. actamat.2006.01.030

7. Juan JS, Nó ML, Schuh CA (2009) Nanoscale shape-memory alloys for ultrahigh mechanical damping. Nat Nanotechnol 4:415-419. doi:10.1038/nnano.2009.142
8. Kiener D, Grosinger W, Dehm G, Pippan R (2008) A further step towards an understanding of size-dependent crystal plasticity: in situ tension experiments of miniaturized single-crystal copper samples. Acta Mater 56:580-592. http://dx.doi.org/10.1016/j. actamat.2007.10.015

9. Lay C, Aseguinolaza I, Chernenko V, Kohl M (2014) In-situ characterization of ferromagnetic shape memory alloy/silicon bimorph nanoactuators, 14th IEEE International Conference on Nanotechnology, 192-195. http://dx.doi.org/10.1109/NANO.2014. 6967989

10. Chernenko VA, Kohl M, Ohtsuka M, Takagi T, L'vov VA, Kniazkyi VM (2006) Thickness dependence of transformation characteristics of $\mathrm{Ni}-\mathrm{Mn}-\mathrm{Ga}$ thin films deposited on alumina: experiment and modeling. Mater Sci Eng 438-440(25):944-947. doi:10.1016/j.msea.2006.02.055

11. Besseghini S, Gambardella A, Chernenko VA, Hagler M, Pohl C, Müllner P, Ohtsuka M, Doyle S (2008) Transformation behavior of $\mathrm{Ni}-\mathrm{Mn}-\mathrm{Ga} / \mathrm{Si}(100)$ thin film composites with different film thicknesses. Eur Phys J Spec Top 158:179-185. http://dx.doi.org/ 10.1140/epjst/e2008-00673-3

12. Singh K, Kaur D (2015) Manifestation of martensitic phase transformation and magneto-caloric properties in high quality magnetron sputtered Ni-Mn-In//Si ultra thin films. Sens Actuators A 236:247-256. http://dx.doi.org/10.1016/j.sna.2015.10.044

13. Teichert N, Auge A, Yüzüak E, Dincer I, Elerman Y, Krumme B, Wende H, Yildirim O, Potzger K, Hütten A (2015) Influence of film thickness and composition on the martensitic transformation in epitaxial Ni-Mn-Sn thin films. Acta Mater 86:279-285. http:// dx.doi.org/10.1016/j.actamat.2014.12.019

14. Buschbeck J, Niemann R, Heczko O, Thomas M, Schultz L, Fähler S (2009) In situ studies of the martensitic transformation in epitaxial Ni-Mn-Ga films. Acta Mater 57(8):2516-2526. doi:10.1016/j.actamat.2009.02.008

15. Chulist R, Böhm A, Oertel C-G, Skrotzki W (2014) Self-accommodation in polycrystalline $10 \mathrm{M} \mathrm{Ni}-\mathrm{Mn}-\mathrm{Ga}$ martensite. J Mater Sci 49(11):3951-3955. doi:10.1007/s10853-013-7996-z

16. Kopitzki K, Herzog P (2004) Einführung in die Festkörperphysik 5. Teubner, Auflage

17. Glassbrenner CJ, Slack GA (1964) Thermal conductivity of silicon and germanium from $3{ }^{\circ} \mathrm{K}$ to the melting point. Phys Rev 134(18):A1058. doi:10.1103/PhysRev.134.A1058

18. Rosenberg SJ (1968) Nickel and its alloys. National Bureau of Standards, Gaithersburg

19. Nepijko SA, Wiesendanger R (1995) Size dependence of the curie temperature of separate nickel particles studied by interference electron microscopy. EPL (Europhysics Letters) 31(9):567. 10.1209/0295-5075/31/9/011

20. Sungtaek Ju Y (2005) Phonon heat transport in silicon nanostructures. Appl Phys Lett 87:153106. doi:10.1063/1.2089178

21. Hopkins PE, Reinke CM, Su MF, Olsson RH, Shaner EA, Leseman ZC, Serrano JR, Phinney LM, El-Kady I (2011) Reduction in the thermal conductivity of single crystalline silicon by phononic crystal patterning. Nano Lett 11(1):107-112. doi:10. 1021/nl102918q

22. Li D, Wu Y, Kim K, Shi L, Yang P, Majumdar A (2003) Thermal conductivity of individual silicon nanowires. Appl Phys Lett 83:2934. http://dx.doi.org/10.1063/1.1616981

23. Tokunaga $\mathrm{T}$, Narushima $\mathrm{T}$, Yonezawa $\mathrm{T}$, Sudo $\mathrm{T}$, Okubo $\mathrm{S}$, Komatsubara S, Sasaki K, Yamamoto T (2012) Temperature distributions of electron beam-irradiated samples by scanning electron microscopy. J Microsc 248(3):228-233. doi:10.1111/j. 1365-2818.2012.03666.x

24. König D, Buenconsejo PJS, Grochla D, Hamann S, PfetzingMicklich J, Ludwig A (2012) Thickness-dependence of the B2B19 martensitic transformation in nanoscale shape memory alloy thin films: zero-hysteresis in $75 \mathrm{~nm}$ thick Ti51Ni38Cu11 thin 
films. Acta Mater 60:306-313. http://dx.doi.org/10.1016/j.acta mat.2011.09.037

25. Ozdemir N, Karaman I, Mara NA, Chumlyakov YI, Karaca HE (2012) Size effects in the superelastic response of Ni54Fe19Ga27 shape memory alloy pillars with a two stage martensitic transformation. Acta Mater 60:5670-5685. http://dx.doi.org/10.1016/j. actamat.2012.06.035

26. Kohl M, Agarwal A, Chernenko VA, Ohtsuka M, Seemann K (2006) Shape memory effect and magnetostriction in polycrystalline $\mathrm{Ni}-\mathrm{Mn}-\mathrm{Ga}$ thin film microactuators. Mater Sci Eng 438-440(25):940-943. doi:10.1016/j.msea.2006.02.062

27. Pons J, Chernenko VA, Cesari E, L'vov VA (2003) Stressstrain-Temperature behaviour for martensitic transformation in $\mathrm{Ni}-\mathrm{Mn}-\mathrm{Ga}$ single crystal compressed along $\langle 001\rangle$ and $\langle 110\rangle$ axes. J Phys IV France 112:939-942. http://dx.doi.org/10.1051/ jp4:20031035

28. Aaltio I, Lahelin M, Söderberg O, Heczko O, Löfgren B, Ge Y, Seppälä J, Hannula S-P (2008) Temperature dependence of the damping properties of $\mathrm{Ni}-\mathrm{Mn}-\mathrm{Ga}$ alloys. Mater Sci Eng 481-482(25):314-317. doi:10.1016/j.msea.2006.12.229

29. Ohtsuka M, Matsumoto M, Itagaki K (2003) Mechanical and shape memory properties of ferromagnetic $\mathrm{Ni} 2 \mathrm{MnGa}$ sputterdeposited films. J Phys IV France 112:899-902. http://dx.doi.org/ 10.1051/jp4:20031026

30. Chernenko VA, Seguí C, Cesari E, Pons J, Kokorin VV (1998) Sequence of martensitic transformations in $\mathrm{Ni}-\mathrm{Mn}-\mathrm{Ga}$ alloys. Phys Rev B 57(1):2659. doi:10.1103/PhysRevB.57.2659
31. Aseguinolaza IR, Reyes-Salazar I, Svalov AV, Wilson K, Knowlton WB, Müllner P, Barandiarán JM, Villa E, Chernenko VA (2012) Transformation volume strain in Ni-Mn-Ga thin films. Appl Phys Lett 101:241912. doi:10.1063/1.4772005

32. Aseguinolaza IR, Orue I, Svalov AV, Wilson K, Müllner P, Barandiarán JM, Chernenko VA (2014) Martensitic transformation in $\mathrm{Ni}-\mathrm{Mn}-\mathrm{Ga} / \mathrm{Si}(100)$ thin films. Thin Solid Films 558(2):449-454. doi:10.1016/j.tsf.2014.02.056

33. Watanabe H, Yamada N, Okaji M (2004) Linear thermal expansion coefficient of silicon from 293 to $1000 \mathrm{~K}$. Int J Thermophys 25:1. doi:10.1023/B:IJOT.0000022336.83719.4

34. Jeong JH, Chung SH, Lee SH, Kwon D (2003) Evaluation of elastic properties and temperature effects in Si thin films using an electrostatic microresonator. J Microelectromech Syst 12(4): 524-530. http://dx.doi.org/10.1109/JMEMS.2003.811733

35. Aaltio I, Söderberg O, Friman M, Glavatskyy I, Ge Y, Glavatska N, Hannula S-P (2009) Determining the liquidus and ordering temperatures of the ternary $\mathrm{Ni}-\mathrm{Mn}-\mathrm{Ga}$ and quaternary Ni-Mn$\mathrm{Ga}-\mathrm{Fe} / \mathrm{Cu}$ alloys. ESOMAT 2009:04001. doi:10.1051/esomat/ 200904001

36. Rösler J, Harders H, Bäker M (2006) Mechanisches Verhalten der Werkstoffe. Teubner, NewYork 